\section{Visual function and ocular features in children and adolescents with attention deficit hyperactivity disorder, with and without treatment with stimulants}

${ }^{1}$ Section of Ophthalmology, Institute of Clinical Neuroscience, The Sahlgrenska Academy at Göteborg University, Göteborg, Sweden

${ }^{2}$ Department of Paediatrics, The Hospital of Skaraborg, Skövde, Sweden

Correspondence:

MA Grönlund, Department of Paediatric

Ophthalmology, Section of Ophthalmology, Institute of Clinical Neuroscience, The Queen Silvia Children's Hospital, The Sahlgrenska University Hospital/Östra, SE 41685 Göteborg, Sweden Tel: + 46313434688 ; Fax: +4631848952. E-mail: marita.gronlund@ neuro.gu.se

Received: 5 July 2005 Accepted in revised form: 29 November 2005 Published online: 3 March 2006

\begin{abstract}
Aims To investigate visual function and ocular features in children with attention deficit hyperactivity disorder (AD/HD) and establish whether treatment with stimulants is reflected in functioning of the visual system. Methods Detailed ophthalmologic evaluations without and with stimulants were performed in 42 children ( 37 boys) with AD/HD, mean age 12 years, and compared with a reference group (ref; $n=50$; mean age 11.9 years; 44 boys). For a comparison between two groups, Mann-Whitney's $U$-test was used for ordered and continuous variables; for dichotomous variables, Fisher's exact test was used. For paired comparison (with and without treatment), sign test was used. Results In all, 83\% had visual acuity of $>0.8$ $(<0.1 \log$ MAR) without treatment, $90 \%$ with stimulants (ref $98 \% ; P=0.032$ and n.s., respectively). Heterophoria was found in $29 \%$ without, and in $27 \%$ with, stimulants (ref $10 \%$; $P=0.038$ and n.s., respectively) and subnormal stereovision ( $>60 \mathrm{~s}$ of arc) in $26 \%$ (ref $6 \%$; $P=0.016)$ without stimulants, and in $27 \%$, with $(P=0.014)$. Abnormal convergence $(>6 \mathrm{~cm}$ or absent) was noted in $24 \%$ (ref $6 \% ; P=0.031$ ) without treatment and in $17 \%$, with (n.s.). Astigmatism ( $\geq 1.0 \mathrm{D})$ was observed in $24 \%$ (ref 6\%; $P=0.03$ ), and signs of visuoperceptual problems in $21 \%$ (ref $2 \% ; P=0.007$ ). We found smaller optic discs $(n=8 / 38)$ and neuroretinal rim areas $(n=7 / 38)(P<0.0001)$ and decreased tortuosity of retinal arteries $(n=6 / 34)$ $(P=0.0002)$ than that of controls.
\end{abstract}

MA Grönlund ${ }^{1}$, E Aring ${ }^{1}$, M Landgren ${ }^{2}$ and A Hellström ${ }^{1}$
Conclusions Children with AD/HD had a high frequency of ophthalmologic findings, which were not significantly improved with stimulants. They presented subtle morphological changes of the optic nerve and retinal vasculature, indicating an early disturbance of the development of these structures.

Eye (2007) 21, 494-502. doi:10.1038/sj.eye.6702240; published online 3 March 2006

Keywords: attention deficit hyperactivity disorder (AD/HD); stimulant medications; visual function; ocular features

Introduction

Attention deficit hyperactivity disorder (AD/HD) is commonly seen among children and adolescents and affects their psychosocial development. ${ }^{1}$ An estimated cumulative incidence of $\mathrm{AD} / \mathrm{HD}$, at the age of 19 years, of $7.5 \%$ has been reported. ${ }^{2}$ The disorder, which is associated with different dysfunctions and abnormalities of the central nervous system (CNS), is treated with stimulants when habilitation and other support are insufficient in preventing that inattention, hyperactivity, and/ or impulsivity that seriously affect learning and/or social behaviour. ${ }^{3,4}$

Structures of the eyes and functions of the visual system can be studied by direct inspection, and evaluated without invasive or painful techniques. Objective measurements can 
be performed on the optic disc and the retinal vessels with a quantitative digital image analysing system. ${ }^{5,6}$ Hence, the eye can be used as an indicator for pre-, perinatal effects on the neural and vascular systems. Examples of such effects are retinopathy of prematurity (ROP), hypoplasia of the optic nerve as in the fetal alcohol syndrome (FAS), ${ }^{7}$ and paretic strabismus in individuals with neuropscyciatric disorders such as autism. ${ }^{8-10}$ Thus, prenatal damage to the CNS has been shown to be reflected in the ocular fundus morphology and in the oculomotor system.

Previous studies have reported that AD/HD may be associated with various dysfunctions of eye motility, for example, saccades and fixation. ${ }^{11-17} \mathrm{Up}$ to now, few studies have been performed on other visual functions and ocular features in patients with AD/HD. Therefore, it has been of interest to examine a group of children with known AD/HD from an ophthalmologic point of view.

The aim of this study was to investigate visual function, for example, visual acuity (VA), stabismus, ocular motility, stereo acuity, convergence, accommodation, refraction, and visual perception as well as ocular features, for example, total axial length (TAL), inner canthal distance (ICD), and palpebral fissure lengths (PFL), as well as ocular fundus morphology in children with AD/HD. We also aimed to establish whether treatment with stimulants is reflected in the functioning of the visual system.

\section{Materials and methods}

In all, 42 of 43 children and adolescents with AD/HD (37 boys, five girls; mean age 12 years, range 6.3-17.6 years) who were being treated with stimulants at the paediatric outpatient clinic in Mariestad, Sweden, participated in the study. The children were examined by a multidisciplinary team representing paediatric ophthalmology, orthoptics, neuropaediatrics, and psychology. The diagnostic criteria were set according to DSM-IV ${ }^{18}$ and the diagnoses were performed by the same physician (ML). The children, who had been on medications for a mean period of 19.5 months (range 2-71 months), came to the investigation without taking their regular drugs in the morning.

The following ophthalmologic tests were first performed without medication:

1. Determination of visual acuity: Visual acuity was tested monocularly at a distance of $3 \mathrm{~m}$ with a linear KM-

Boks chart. ${ }^{19}$ Near vision was tested binocularly at a distance of $0.33 \mathrm{~m}$. One 6-year-old boy was tested with the Lea symbols chart ${ }^{20}$ both on and off treatment as he could not perform VA testing with the
KM chart. Values were noted in decimal format and transferred to $\log$ MAR units.

2. Investigation of strabismus and ocular motility: Heterotropia was investigated using monolateral cover test. Heterophoria was detected by an alternate cover test and was defined as a latent deviation of exophoria $>4$ prism diopters $(\mathrm{pD})$ or esophoria $>2 \mathrm{pD}$ at near $(0.33 \mathrm{~m})$ and / or at distance $(3 \mathrm{~m}) .{ }^{21}$ Eye movement registrations (fixation, saccades, and smooth pursuit) by using the Orbit infrared reflection method (Orbit, IOTA Inc., Sundsvall, Sweden) were performed. The results from the Orbit registration will be presented elsewhere (Aring $\mathrm{E}$ et al, in manuscript, 2005).

3. Testing of stereo acuity: The TNO random-dot test was used and children who failed were tested with Lang I or Titmus test. Subnormal stereo acuity was defined as $>60$ s of arc and was considered absent if all three tests were negative.

4. Near point of convergence: For near point of convergence (NPC) evaluation in $\mathrm{cm}$, the RAF ruler was used. ${ }^{22}$ A mean value of three measurements was recorded. This method has a high reproducibility although, the near limit is only $6 \mathrm{~cm}$.

5. Near point of accommodation: Near point of accomodation (NPA) was measured binocularly in diopters (D), with the RAF ruler. ${ }^{23}$ A mean value of three measurements was recorded.

Thereafter, the children were given their regular drugs, individually tailored doses of short-acting stimulants (methylphenidate $(n=40), 0.14-1.1 \mathrm{mg} / \mathrm{kg}$, or amphetamine $(n=2), 0.24-0.61 \mathrm{mg} / \mathrm{kg})$. After at least $60 \mathrm{~min}$, all tests above were performed in the same order with medication. In addition, the following tests were performed:

6. Refraction under cycloplegia: This was performed with an autorefractometer (Topcon RM-A7000B) after a single instillation of a mixture of cyclopentolate $(0.85 \%)$ and phenylephrine $(1.5 \%)$. Significant refractive errors were defined as a spherical equivalent (SE) of myopia $\geq 0.5 \mathrm{D}$ or hyperopia $\geq 2.0 \mathrm{D}$. Astigmatism was assessed at a level of $\geq 1.0 \mathrm{D}$ and anisometropia, at a level of $\geq 1.0 \mathrm{D}$ SE. Individuals were considered to be myopic if one or both eyes were myopic; hyperopic if one or both eyes were hyperopic, as long as no eye was myopic; and astigmatic if one or both eyes were astigmatic. $^{23}$

7. Assessment of ocular dimensions: The ICD was measured in mm with a ruler, as were the right and left PFL. ${ }^{24}$ The total axial length (TAL) was measured by ultrasound biometry (Paxis Version 2.01 
BIONVISION). The mean value of ten measurements (if available) of the TAL of each eye was recorded.

8. Examination of the anterior segment, media, and ocular fundus: The anterior segment of the eye was examined using a slit lamp and the ocular fundus by indirect ophthalmoscopy.

9. Photography of the ocular fundus for quantitative digital image analysis: Ocular fundus photographs were taken and optic disc, optic cup and neuroretinal rim area as well as tortuosity of veins and arteries and number of vascular central branching points were analysed using a specially designed-computerassisted digital mapping system. ${ }^{5,6}$

10. History taking of visual perception: A structured history was taken regarding visual perceptual problems in five different areas: recognition, orientation, perception of depth, perception of motion, and simultaneous perception. ${ }^{25}$ In all, 12 selected questions regarding visual perceptual-cognitive problems were translated into Swedish. Whereas questions 1-4 dealt with recognition, questions 5-7 addressed orientation, while question 8 asked about perception of depth, questions 9 and 10 about perception of motion, and questions 11 and 12 about simultaneous perception. The structured clinical history was taken from the children and their parents together, giving the children/ parents the opportunity to discuss the questions.

The whole investigation (including paediatric and psychologic evaluation) took in average $4 \mathrm{~h}$ to perform in each child, and the time between the two ophthalmological sessions (without and with stimulants) was approximately $2 \mathrm{~h}$ (Figure 1 ).

\section{Medical records}

Medical records from maternity and Child Health Care units, delivery units, schools, as well as from hospitals and outpatient clinics where appropriate were collected and scrutinized. The mean birth weight for the study cohort was $3420 \mathrm{~g}$ (range 1990-4625 g; $n=41$ ) with a mean birth length of $50 \mathrm{~cm}$ (range $46-55 \mathrm{~cm} ; n=40$ ) and a mean head circumference at birth of $34 \mathrm{~cm}$ (range $32-37 \mathrm{~cm} ; n=39)$. Three children out of $41(7 \%)$ were born preterm and four children $(10 \%)$ were small for gestational age (SGA). In order to compare weight, length and head circumference at birth, as well as at assessment, these data were converted to standard deviation scores (SDSs) on the basis of Swedish reference values $^{26,27}$ (Table 1). Two children were adopted, one boy originated from Colombia and another from Poland. One child was born in Germany.

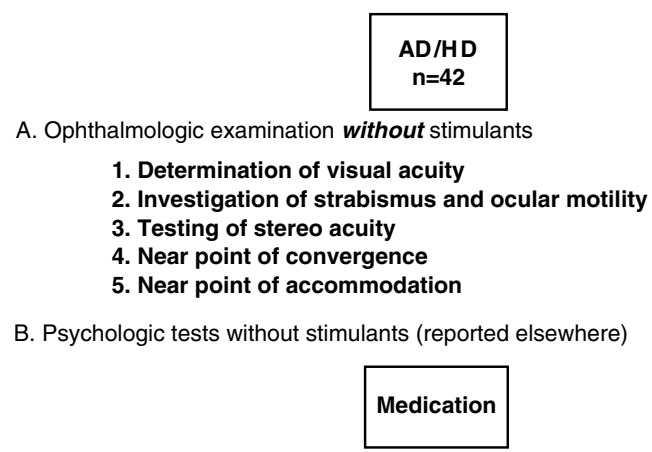

C. Pediatric examination (reported elsewhere)

D. Ophthalmologic examination with stimulants 1.-5. repeated

E. Psychologic test with stimulants

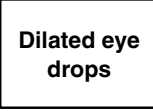

F. Ophthalmologic examination continued

6. Refraction under cycloplegia

7. Assessment of ocular dimensions

8. Examination of the anterior segment, media, and ocular fundus 9. Photography of the ocular fundus for quantitative digital image analysis

10. History taking of visual perception

Figure 1 Flow chart showing study design of 42 patients with attention deficit hyperactivity disorder (AD/HD) tested without and with stimulants.

Table 1 Weight, length and head circumference at birth as well as at assessment, converted to standard deviation scores (SDSs) on the basis of Swedish reference values, in the group of children with AD/HD $(n=42)$ and in the reference group $(n=50)$

\begin{tabular}{lccr}
\hline & $\begin{array}{c}\text { Children with AD/HD } \\
\text { Mean SDS (range) }(\mathrm{n}=42)\end{array}$ & $\begin{array}{c}\text { Reference group } \\
\text { Mean SDS (range) }(\mathrm{n}=50)\end{array}$ & $\begin{array}{c}\text { P-value } \\
\text { Birth weight }\end{array}$ \\
Birth length & $-0.16(-3.0-3.0)(n=41)$ & $0.4(-3.0-3.0)$ & 0.05 \\
Head circumference at birth & $-0.2(-2.5-2.0)(n=40)$ & $0.2(-1.8-2.8)$ & 0.07 \\
Weight at assessment & $-0.24(-2.5-3.5)(n=39)$ & $0.08(-2.0-2.0)$ & 0.12 \\
Length at assessment & $0.4(-2.7-3.7)$ & $0.16(-2.2-3.0)(n=43)$ & 0.44 \\
Head circumference at assessment & $-0.1(-2.7-3.0)$ & $-0.05(-2.8-2.8)(n=43)$ & 0.93 \\
\hline
\end{tabular}

Values are given as means (ranges). 


\section{Reference groups}

Ophthalmologic data were compared with data for an age- and sex-matched reference group ('ref') $(n=50$, six girls and 44 boys, mean age 11.9 years) consisting of children living in the same region as the children with AD/HD. The reference group was selected from a group of school children $(n=143)$ recriuted from four different pre-schools/schools in the Göteborg area (see under statistical analysis). The schools, one school from the downtown area, two suburban schools and one school from the more rural part, were selected to reflect the socio-economic mix of the area from which the study cohort was drawn. These children were not masked nor were the examiners. The mean birth weight for the reference group was $3698 \mathrm{~g}$ (range 2520-4760 g) with a mean birth length of $51 \mathrm{~cm}$ (range $46-56 \mathrm{~cm}$ ). The mean head circumference at birth was $35 \mathrm{~cm}$ (range $32-$ $38.5 \mathrm{~cm}$ ). Two children (4\%) from the reference group had been born preterm and none had been born SGA. None of the children in this group had AD/HD, according to medical records. Another 99 healthy Swedish children and adolescents between 3 and 19 years of age and born at term constituted a reference group for evaluation of ocular fundus morphology. ${ }^{28}$

The study was approved by the Ethics Committee at the Medical Faculty, The Sahlgrenska Academy at Göteborg University, Göteborg, Sweden. Informed consent was obtained from the parents of all the children participating in the study.

\section{Statistical analysis}

Means, standard deviations (SDs), SDS's, medians, and ranges were calculated for descriptive purposes. For a comparison between two groups, Mann-Whitney's $U$-test was used for ordered and continuous variables; for dichotomous variables, Fisher's exact test was used. For paired comparison (with and without treatment), sign test was used. The reference group for this study was selected individual by individual, by minimizing the maximal $t$-values between the group of children with AD/HD and a reference group of 143 healthy Swedish school-aged children, over the variables age and sex. The ocular fundus variables measured by the digital image analysis were calculated from the mean of the two eye measurements of each child. Where the photograph of only one eye was sufficiently good, the values for that eye were used. The hypothesis of no difference in median values between the children with $\mathrm{AD} / \mathrm{HD}$ and controls, for the different variables mentioned above, was tested by means of the Mann-Whitney's $U$-test. Test results were considered to be significant if $P<0.05$. Cut-points were chosen before investigation, according to cited references.

\section{Results}

Without treatment, there was a significant difference in proportion of children with VA $>0.8(<0.1 \log \mathrm{MAR})$ in the better eye at distance between children with AD/HD and the reference group, but not when treated with stimulants (Table 2). However, no significant difference in proportion of children with VA $>0.8$ was found without and with treatment. Most of the children with $\mathrm{AD} / \mathrm{HD}(36 / 38 ; 95 \%)$ had binocular VA at near between 0.8 and 1.0 (0.1-0.0 logMAR) without stimulants. No statistical difference was found between groups or between treatment and nontreatment with stimulants, regarding VA at near.

Heteroptropia without stimulants was observed in $5 / 41(12 \%)$ children (esotropia, $n=4$; exotropia, $n=1$ ) (ref $6 \% ;$ n.s), and in the same number with stimulant medication. However, one child could not be examined properly without medication; and on treatment, she was found to be esotropic. The child with exotropia became exophoric on treatment. Significant differences between the $\mathrm{AD} / \mathrm{HD}$ group and the reference group were found regarding heterophoria and NPC without but not with stimulants, regarding stereo acuity both without and with stimulants (Table 2). All, but one, of the children tested ( $n=38$ ) had an NPA in the normal range, according to Duane's standard curve of accommodation, ${ }^{29}$ both without and with stimulants. The individual with abnormal NPA was a 16-year-old boy with dyslexia.

The mean SE for right eyes in the study cohort was +1.16 (SD 1.91; range -2.0 to +8.25 ) and for left eyes, +1.24 (SD 1.90; range -1.75 to +9.25 ) when compared with a mean SE of +0.59 (SD 1.19; range -2.13 to +2.75 ) for right eyes in the reference group (n.s.) and +0.68 (SD 1.40; range -2.75 to +6.50 ) for left eyes (n.s.). Table 3 shows children who in cycloplegia had refractive errors as well as children who wore glasses at the time of the examination.

Mean values (SD) for ICD was $30.9 \mathrm{~mm}$ (3.05) for the children with AD/HD compared with $29.1 \mathrm{~mm}$ (1.99) for the reference group $(P=0.001)$. Mean values for PFLs did not differ between the two groups. Mean values (SD) for right TAL $(n=31)$ was $22.7 \mathrm{~mm}(0.99)$ (ref $(n=46)$ $23.0 \mathrm{~mm}(0.76) ;$ n.s. $)$ and for left TAL $(n=32) 22.6 \mathrm{~mm}$ (0.80) (ref $(n=40) 23.1 \mathrm{~mm}(0.78) ; P=0.01)$.

Four children had epicanthic folds. Nystagmus was recorded in one child both with and without stimulants. Five cases with notable small optic discs were observed by ophthalmoscopy and one child had increased tortuosity of the retinal vessels. In the reference group no 
Table 2 Number (\%) of children with AD/HD and controls (ref), who were recorded to have VA $>0.8(<0.1$ logMAR) at distance in the better eye, heterophoria (exophoria $>4 \mathrm{pD}$ or esophoria $>2 \mathrm{pD}$ ), stereo acuity ( $\geq 60^{\prime \prime}$ or negative), and near point of convergence (NPC) ( $>6 \mathrm{~cm}$ or absent), both with and without stimulants

\begin{tabular}{|c|c|c|c|c|}
\hline Ophthalmologic variable & $\begin{array}{c}A D / H D(\mathrm{n}=42) \\
\mathrm{n}(\%)\end{array}$ & $\begin{array}{l}\operatorname{Ref}(\mathrm{n}=50) \\
\mathrm{n}(\%)\end{array}$ & $\begin{array}{l}\text { P-value without/with } \\
\text { stimulants vs ref }\end{array}$ & $\begin{array}{c}\text { P-value without vs with } \\
\text { stimulants }\end{array}$ \\
\hline \multicolumn{5}{|l|}{$V A>0.8(<0.1 \log M A R)$} \\
\hline \multicolumn{5}{|l|}{ At distance, better eye } \\
\hline $\begin{array}{l}\text { Without/with } \\
\text { stimulants }\end{array}$ & $35(83 \%) / 38(90 \%)$ & $49(98 \%)$ & $0.03^{*} /$ n.s. & 0.25 \\
\hline \multicolumn{5}{|c|}{$\begin{array}{l}\text { Heterophoria (exophoria }>4 p D \\
\text { or esophoria }>2 p D \text { ) }\end{array}$} \\
\hline $\begin{array}{l}\text { Without/with } \\
\text { stimulants }\end{array}$ & $12(29 \%)^{\mathrm{a}} / 11(27 \%)^{\mathrm{a}}$ & $5(10 \%)$ & $0.038^{*} /$ n.s. & 0.62 \\
\hline \multicolumn{5}{|c|}{ Stereo acuity ( $\geq 60^{\prime \prime}$ or negative) } \\
\hline $\begin{array}{l}\text { Without/with } \\
\text { stimulants }\end{array}$ & $11(26 \%) / 11(27 \%)^{\mathrm{a}}$ & $3(6 \%)$ & $0.016^{*} / 0.014^{*}$ & 1.00 \\
\hline \multicolumn{5}{|l|}{$N P C(>6 \mathrm{~cm}$ or absent $)$} \\
\hline $\begin{array}{l}\text { Without/with } \\
\text { stimulants }\end{array}$ & $10(24 \%) / 7(17 \%)^{\mathrm{a}}$ & $3(6 \%)$ & $0.03^{*} /$ n.s. & 0.29 \\
\hline
\end{tabular}

*Statistically significant.

${ }^{\mathrm{a}} n=41 ; \mathrm{VA}=$ visual acuity; NPC $=$ near point of convergence.

Table 3 Number (\%) of children with AD/HD and controls (ref), who after cycloplegia were measured to be hyperopic ( $\geq 2.0 \mathrm{D}$ SE) and myopic ( $\geq 0.5 \mathrm{D} \mathrm{SE})$, as well as children who were astigmatic $(\geq 1.0 \mathrm{D})$ or anisometropic $(\geq 1.0 \mathrm{D} \mathrm{SE})$ or wore glasses

\begin{tabular}{lccc}
\hline Refraction & AD/HD $(n=42) \mathrm{n}(\%)$ & Ref $(\mathrm{n}=50) \mathrm{n}(\%)$ & P-value \\
\hline Myopia ( $\geq 0.5 \mathrm{D}$ SE) & $8(19 \%)$ & $7(14 \%)$ & 0.71 \\
Hyperopia $(\geq 2.0 \mathrm{D}$ SE) & $10(24 \%)$ & $5(10 \%)$ & 0.13 \\
Astigmatism $(\geq 1.0 \mathrm{D})$ & $10(24 \%)^{\mathrm{a}}$ & $3(6 \%)^{\mathrm{b}}$ & $0.03^{*}$ \\
Anisometropia $(\geq 1.0 \mathrm{D} \mathrm{SE})$ & $5(12 \%)$ & $3(6 \%)$ & 0.53 \\
Wearing glasses & $13(31 \%)$ & $7(14 \%)$ & 0.09 \\
\hline
\end{tabular}

*Statistically significant.

${ }^{a}$ Astigmatism in this group ranged from $1.0 \mathrm{D}$ to $2.25 \mathrm{D}$.

${ }^{\mathrm{b}}$ Astigmatism in the reference group ranged from $1.0 \mathrm{D}$ to $1.50 \mathrm{D}$.

$\mathrm{D}=$ diopter; $\mathrm{SE}=$ spherical equivalent.

anomalies of the anterior parts, media or fundus were found.

We were able to analyse ocular fundus photographs in 38/42 children with AD/HD (90\%) concerning optic disc, cup, and neuroretinal rim area (Figure 2). Vessel characteristics were analysed in 34/42 children (81\%) (Figure 2). The children with AD/HD had a significantly smaller optic disc area (median $2.01 \mathrm{~mm}^{2}$; range 1.28-2.69) than that seen in the controls (median $2.41 \mathrm{~mm}^{2}$; range $\left.1.55-5.32\right)(P<0.0001)$ as well as a smaller neuroretinal rim area (median $1.78 \mathrm{~mm}^{2} ; 1.21-$ 2.48), compared with the controls (median $2.07 \mathrm{~mm}^{2}$; range 1.31-3.86) $(P<0.0001)$ (Figures $2 \mathrm{a}$ and 3$)$. The $\mathrm{AD} / \mathrm{HD}$ children as a group had also a smaller cup area (median $0.21 \mathrm{~mm}^{2}$; range $0.00-0.76$ ) than that of the controls (median $0.33 \mathrm{~mm}^{2}$; range $\left.0.00-1.61\right)(P=0.005)$ (Figure 2a). A lower index of tortuosity for arteries (ITA) in the AD/HD group than that of the controls was also found (AD/HD children: median index 1.07; range 1.04-1.12, v. reference children: 1.09; range 1.04-1.22) $(P=0.0002)$, as was a lower index of tortuosity for veins (ITV) (AD/HD group: median index 1.06; range 1.031.09 , v. reference group: 1.06 ; range $1.03-1.21)(P=0.003)$ (Figures $2 \mathrm{~b}$ and 3 ). However, no difference was found in the number of central branching points between the two groups.

Visual perceptual problems were reported in 9/42 children $(21 \%)($ ref $1 / 50 ; 2 \%)(P<0.007)$ in one or more (median 2; range 1-5) of the areas investigated (Figure 4). The most frequent areas of visuoperceptual problems reported were simultaneous perception $(n=5)$, orientation $(n=5)$, and motion perception $(n=5)$, followed by depth perception $(n=4)$ and recognition $(n=4)$. 

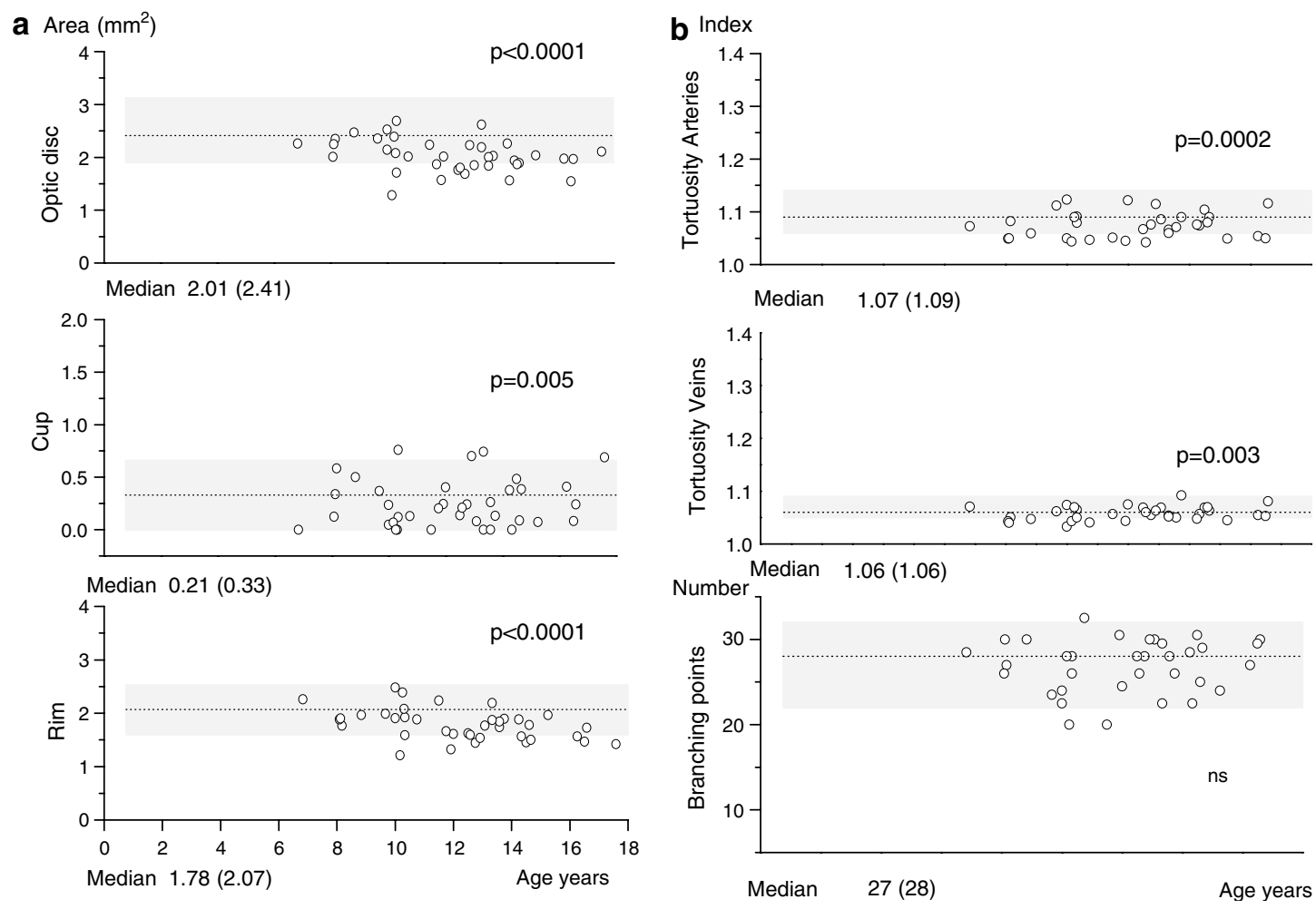

Figure 2 (a) Individual and median values for optic disc, cup, and neuroretinal rim areas in 38 children with AD/HD. The shaded area depicts the 5 th to the 95 th centile range, and the centre line indicates the median for the healthy reference group. ${ }^{28}$ (b) Individual and median values for index of tortuosity of arteries (ITA) and veins (ITV) as well as number of branching points in 34 children with $\mathrm{AD} / \mathrm{HD}$. The shaded area depicts the 5th-95th centile range, and the centre line indicates the median for the healthy reference group. ${ }^{28}$

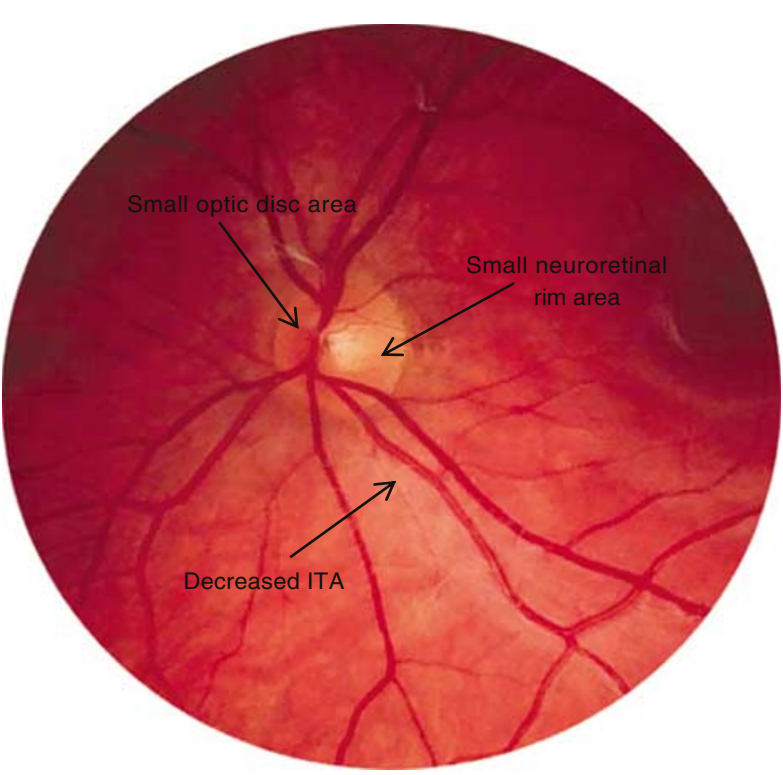

Figure 3 Fundus photograph of a 12 year old boy with AD/ HD, showing an example of a small optic disc area, a small neuroretinal rim area and decreased index of tortuosity for retinal arteries (ITA) in the retina.

\section{Discussion}

In the present study a high frequency of ocular and visual abnormalities was found in children with AD/HD. Altogether, $76 \%$ had ophthalmologic findings including subnormal VA, strabismus, reduced stereo vision, absent or subnormal NPC, refractive errors, small optic discs and/or signs of cognitive visual problems.

With regard to VA, there was a significant difference in the proportion of children who performed well on the VA test at distance $>0.8(<0.1 \log \mathrm{MAR})$, between children with $\mathrm{AD} / \mathrm{HD}$ without stimulants $(83 \%)$ and reference children (98\%). With medication, $90 \%$ of the children with AD/HD had VA $>0.8$ and no significant difference between the groups was found. A variety of different psychophysical tests are used when measuring VA, depending on the age and the cooperativeness of the child. Recognition acuity (optotype acuity) is used in older children and VA assessment is on the basis of identification of letters or symbols (optotypes) of decreasing size, for example, KM-Boks chart. The fact that the children with $\mathrm{AD} / \mathrm{HD}$ perform better on VA testing with stimulants than without, compared with 

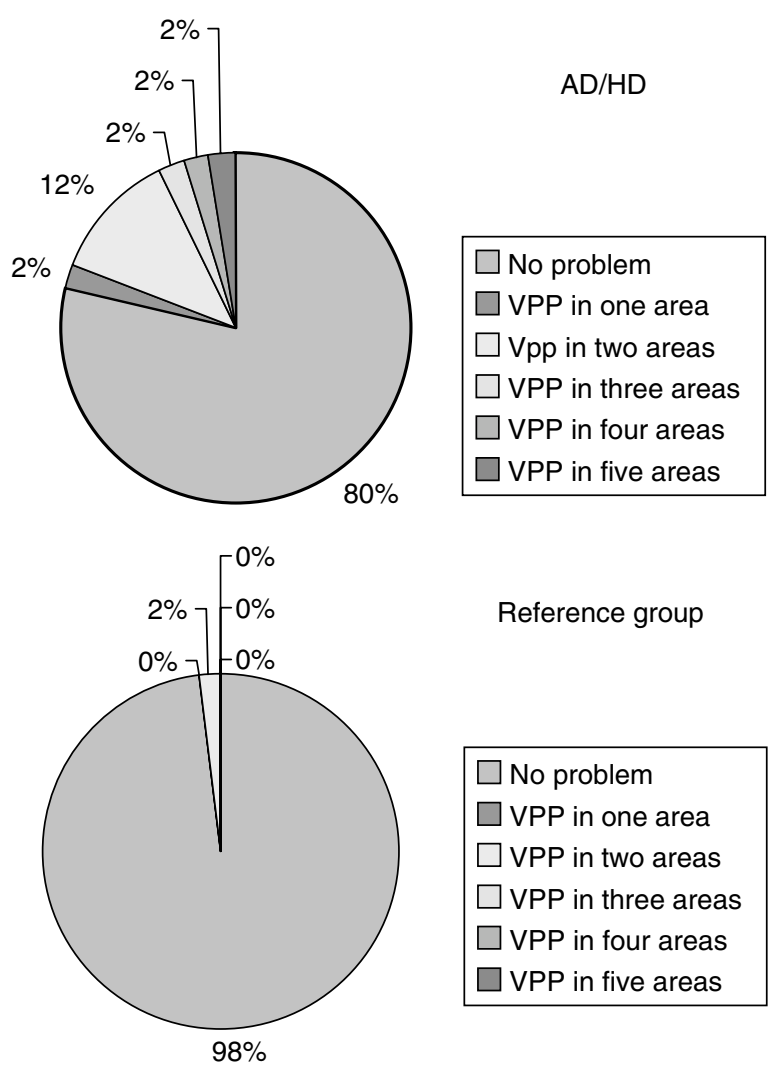

Reference group

$\square$ No problem
$\square$ VPP in one area
$\square$ VPP in two areas
$\square$ VPP in three areas
$\square$ VPP in four areas
$\square$ VPP in five areas

Figure 4 Proportion of children with AD/HD ( $n=42)$ (top) and children in the reference group $(n=50)$ (bottom), who either exhibited no visuoperceptual problem (VPP) or had problems in one or more of the five areas tested (recognition, orientation, depth perception, motion perception, and simultaneous perception), as recorded by structured history taking.

controls may be speculated that they concentrated better with stimulants; however, the training effect can not be excluded as the children performed the test twice within approximately two hours. It is important to realize that VA reflects the cooperativeness of that child in that unique situation.

In one child with heterotropia, the change to heterophoria with medication might be due to better central nervous control. We found a significant difference of heterophoria in children with AD/HD when compared with the reference group without, but not with, stimulants. In one child with ortophoria without treatment and heterophoria on stimulants, the change might be the result of better ability to fixate making a correct diagnosis possible. In all, $25 \%$ of the children had subnormal or negative stereo acuity. It is possible that this high percentage was due to lack of attention. We also found a high proportion of children (24\%) with no, or subnormal, NPC without medication. This was decreased to $17 \%$ with stimulants.
The children with AD/HD had smaller optic disc areas and smaller neuroretinal rim areas than that of controls (Figure 2a). Very preterm birth has previously been associated with subnormal optic disc and neuroretinal rim areas, ${ }^{30}$ and an association between a reduced rim area and intra-uterine growth retardation at 18 years of age has recently been found. ${ }^{31} \mathrm{~A}$ decrease in neuroretinal rim area reflects either a decrease in the number of axons or a reduction in axonal volume in the optic nerve. Also, the children with $\mathrm{AD} / \mathrm{HD}$ as a group showed a decreased ITA and ITV, compared with controls (Figure 2b). Decreased ITA/ITV has not been found in any other group of children previously investigated. In contrast, increased tortuosity of the retinal vessels has previously been found in children born preterm and in children with FAS. ${ }^{6,7}$ Seven children in the present study group had been born preterm (none very preterm) and/or SGA and none had FAS, according to the medical records. To our knowledge, this is the first study reporting morphological abnormalities in neuronal and vascular tissues of the eye in children with AD/HD, indicating an early disturbance of the development of these structures. In all, $21 \%$ of the children with $\mathrm{AD} / \mathrm{HD}$ (ref $2 \%$ ) in the present study showed signs of cognitive visual problems (Figure 4). It is notable that the children can have visuoperceptual problems despite good VA and normal IQ (>70). In 7/9 children with visuo-cognitive problems, one or more fundus abnormalities were found.

The examiners in the present study were not masked to either the diagnoses or to the treatment status of the children. For measurement of most of the variables, it would have been desirable with masked examiners. Unfortunately, this was not practical. However, the person who analysed the ocular fundus photographs with the digital analysing system was not aware of the diagnoses of the children.

Attention deficit hyperactivity disorder is a heterogenous disorder of unknown aetiology. It has been associated with dysfunction of the frontostriatal pathways and signs of cortical disinhibition, ${ }^{32,33}$ with reduction of regional cerebral blood flow in the orbitofrontal cortex, ${ }^{34}$ and with cortical abnormalities, such as abnormal morphology in the frontal cortices and reduced regional brain size localised to inferior portions of dorsal prefrontal cortices. ${ }^{35}$ Both dopamine and norepinephrine are important in the pathophysiology as well as in the response to stimulants in AD/HD. ${ }^{31}$ The disorder is diagnosed in males four to nine times more often than in females, ${ }^{18}$ which is in accordance with our study cohort consisting of five girls and 37 boys. According to Sweeney et al, ${ }^{36}$ recent oculomotor studies have made significant contributions to the understanding of neurodevelopmental disorders such as AD/HD. It is 
recently reported by Feifel $e t$ al ${ }_{1}^{17}$ that $\mathrm{AD} / \mathrm{HD}$ in adults is associated with deficit in saccadic inhibition, which implicates abnormalities in prefrontal cortex-basal ganglia circuitry in this disorder. Deficits in inhibitory mechanisms may underlie the inattention characteristic of AD/HD. Gould et al, ${ }^{14}$ showed that children with $\mathrm{AD} / \mathrm{HD}$ did not maintain visual fixation and that children did without $\mathrm{AD} / \mathrm{HD}$. In contrast, smooth-pursuit eye movements have not been found to be impaired in $\mathrm{AD} / \mathrm{HD}^{12}$

In conclusion, children with $\mathrm{AD} / \mathrm{HD}$ have a high frequency of ocular and visual dysfunctions including visuoperceptual problems. The children had an increased proportion of heterophoria and poorer performance on visual acuity and convergence tests without, but not with, stimulants when compared with controls. However, treatment with stimulants caused no significant difference in visual function. Interestingly, the children in the present study showed subtle morphological changes of the optic nerve and retinal vasculature, indicating an early disturbance of the development of neural and vascular tissues in the CNS.

\section{Acknowledgements}

The Göteborg Medical Society, the W \& M Lundgrens Vetenskapsfond II, and Research and Development of the Region Västra Götaland supported this study. Parts of the study have been presented at the Riksstämman meeting held in Göteborg, Sweden, in November 2004 and at the ARVO Annual Meeting held in Fort Lauderdale, FL, USA, in May 2005. The authors thank B Melander and A Erngren for their technical assistance and Dr A-L Hård for valuable criticism of the manuscript. E Jaensson and G Ekeroth of the Statistiska Konsultgruppen, Göteborg, Sweden are gratefully acknowledged for their help with the statistical analyses.

\section{References}

1 Landgren M. Deficits in attention, motor control and perception-DAMP. Epidemiologic, etiologic, diagnostic and learning aspects. Thesis, Göteborg University, Sweden; 1999.

2 Barbaresi W, Katusic S, Colligan R, Weaver A, Pankratz V, Mrazek Jacobsen S. How common is attention-deficit/ hyperactivity disorder? Towards resolution of the controversy: results from a population-based study. Acta Paediatr Suppl 2004; 93: 55-59.

3 Wigal T, Swanson JM, Regino R, Lerner MA, Soliman I, Steinhoff $\mathrm{K}$ et al. Stimulant medications for the treatment of AD/HD: efficacy and limitations. Ment Retard Dev Disabil Res Rev 1999; 5: 215-224.

4 Kempton S, Vance A, Maruff P, Luk E, Costin J, Pantelis C. Executive function and attention deficit hyperactivity disorder: stimulant medication and better executive function performance in children. Psychol Med 1999; 29: 527-538.

5 Strömland K, Hellström A, Gustafsson T. Morphometry of the optic nerve and retinal vessels by computer-assisted image analysis. Graef Arch Clin Exp Ophthalmol 1995; 233: 150-153.

6 Hellström A. The optic disc and retinal vessels in children with adverse events during pre- and perinatal life. Thesis, Göteborg University, Göteborg, Sweden 1997.

7 Strömland K. Ocular abnormalities in the fetal alcohol syndrome. Acta Ophthalmol 1985; 171(Suppl): 1-50.

8 Strömland K, Nordin V, Miller M, Åkerström B, Gillberg C. Autism in thalidomide embryopathy. A population study. Dev Med Child Neurol 1994; 36: 351-356.

9 Miller M, Strömland K, Gillberg C, Johansson M, Nilsson EW. The puzzle of autism: an ophthalmologic contribution. Tr Am Ophth Soc 1998; XCVI: 369-387.

10 Rodier P. The early origins of autism. Sci Am 2000; 282: 38-45.

11 Ross RG, Hommer DW, Breiger D, Varley C, Radant A. Eye movement task related to frontal lobe functioning in children with attention deficit disorder. I Am Acad Child Adolesc Psychiatry 1994; 33: 869-874.

12 Castellanos FX, Marvasti FF, Ducharme JI, Walter JM, Israel $\mathrm{ME}, \mathrm{Krain} \mathrm{A}$ et al. Executive function oculomotor tasks in girls with ADHD. J Am Acad Child Adolesc Psychiarty 2000; 39: 644-650.

13 Mostofsky SH, Lasker AG, Cutting LE, Denckla MB, Zee DS. Oculomotor abnormalities in attention deficit hyperactivity disorder. Neurology 2001; 57: 423-430.

14 Gould TD, Bastain TM, Israel ME, Hommer DW, Castellanos FX. Altered performance on an ocular fixation task in attention-deficit/hyperactivity disorder. Biol Psychiatry 2001; 50: 633-635.

15 Klein C, Fischer Jr B, Fischer B, Hartnegg K. Effects of methylphenidate on saccadic responses in patients with ADHD. Exp Brain Res 2002; 145: 121-125.

16 Munoz DP, Armstrong IT, Hampton KA, Moore KD. Altered control of visual fixation and saccadic eye movements in attention deficit hyperactivity disorder. J Neurophysiol 2003; 90: 503-514.

17 Feifel D, Farber RH, Clementz BA, Perry W, Anllo-Vento L. Inhibitory deficits in ocular motor behavior in adults with attention-deficit/hyperactivity disorder. Biol Psychiatry 2004; 56: 333-339.

18 American Psychiatric Association. Diagnostic and Statistical Manual of Mental Disorders, 4th ed. American Psychiatric Association: Washington, DC, 1994.

19 Hedin A, Olsson K. Letter legibility and the construction of a new visual acuity chart. Ophthalmologica 1984; 189: 147-156.

20 Graf MH, Becker R, Kaufmann H. Lea symbols: visual acuity assessment and detection of amblyopia. Graefes Arch Clin Exp Ophthalmol 2000; 238: 53-58.

21 Moses RA. Adler's Physiology of the eye, 5th ed. Mosby: St Louis, Missouri, 1970.

22 Von Noorden G, Campos E. Binocular Vision and Ocular Motility: Theory and Management of Strabismus. Mosby: St Louis, Missouri, 2002.

23 Negrel AD, Maul E, Pokharel GP, Zhao J, Ellwein LB. Refractive error study in children: sampling and measurement methods for a multi-country survey. Am J Ophthalmol 2000; 4: 421-426. 
24 Hall JG, Froster-Iskenius UG, Allanson JE. Handbook of normal physical measurements. Oxford University press: Oxford, 1989, pp 132-157.

25 Dutton G, Ballantyne J, Boyd G, Bradnam M, Day R, McCulloch $\mathrm{D}$ et al. Cortical visual dysfunction in children: a clinical study. Eye 1996; 10: 302-309.

26 Albertsson Wikland K, Luo ZC, Niklasson A, Karlberg J. Swedish population-based longitudinal reference values from birth to 18 years of age for height, weight and head circumference. Acta Paediatr 2002; 91: 739-754.

27 Albertsson Wikland K, Karlberg J. Natural growth in children born small for gestational age with and without catch-up growth. Acta Pediatr 1994; 399(Suppl): 64-71.

28 Hellström A, Svensson E. Optic disc size and retinal vessel characteristics in healthy children. Acta Ophthalmol 1998; 76: 260-267.

29 Duane A. Studies in monocular and binocular accommodation with their clinical applications. Am J Ophthalmol 1922; 5: 865.

30 Hellström A, Hård A-L, Svensson E, Niklasson A. Ocular fundus abnormalities in children born before 29 weeks of gestation: a population-based study. Eye 2000; 14: 324-329.
31 Ley D, Marsal K, Dahlgren J, Hellström A. Abnormal retinal optic nerve morphology in young adults after intrauterine growth restriction. Pediatr Res 2004; 56: 139-143.

32 Solanto MV. Dopamine dysfunction in AD/HD: integrating clinical and basic neuroscience research. Behav Brain Res 2002; 130: 65-71.

33 Willis WG, Weiler MD. Neural substrates of childhood attention-deficit/hyperactivity disorder: electroencephalographic and magnetic resonance imaging evidence. Dev Neuropsychol 2005; 27: 135-182.

34 Lee JS, Kim BN, Kang E, Lee DS, Kim YK, Chung JK et al. Regional cerebral blood flow in children with attention deficit hyperactivity disorder: comparison before and after methylphenidate treatment. Hum Brain Mapp 2005; 24: 157-164.

35 Sowell ER, Thompson PM, Welcome SE, Henkenius AL, Toga AW, Peterson BS. Cortical abnormalities in children and adolescents with attetion-deficit-hyperactivity disorder. Lancet 2003; 362: 1699-1707.

36 Sweeney JA, Takarae Y, Macmillan C, Luna B, Minshew N. Eye movements in neurodevelopmental disorders. Curr Opin Neurol 2004; 17: 37-42. 